\title{
A putative mechanism of the Sodium/lodide Symporter regulation during repetitive administration of stable lodide described by a Systems Biology approach
}

\author{
David Cohen ${ }^{1}$, Dalila Lebsir $^{1}$, Karine Tack ${ }^{1}$, Marc Benderitter ${ }^{2}$, and Mâ̂mar Souidi ${ }^{1}$ \\ ${ }^{1}$ Institut de Radioprotection et de Sûreté Nucléaire (IRSN), PSE-Santé/SESANE/LRTOX, 92262 \\ Fontenay-aux-Roses, France \\ ${ }^{2}$ Institut de Radioprotection et de Sûreté Nucléaire (IRSN), PSE-Santé/SERAMED, 92262 Fontenay- \\ aux-Roses, France
}

\section{Abstract}

A single dose of potassium iodide (KI) against a prolonged exposure to repeated radioactivity might not be effective enough to protect the thyroid. Our group have shown that a repetitive dose of KI for eight days offers efficient protection without adverse effects in male rats [1].

However, we also have shown that the expression of the genes involved in the WolffChaikoff effect changes during this period. Notably, a decrease in the sodium/iodide symporter (nis) gene expression has been observed [1]. This effect may result in hypothyroidism due to a decrease in thyroid hormones.

NIS is responsible for the uptake of KI and thus plays an important role in the WolffChaikoff effect. The mechanism of a single dose of KI on the toxicity of the thyroid is well known [2], in contrast to repetitive administration of KI for eight days.

In the present study, we try to understand the Wolff-Chaikoff regulation and its molecular constituents during repetitive administration of KI. For this purpose, we have constructed manually a biochemical reaction network that is visualised as a "geographical" map of a single thyrocyte cell depicting the iodide and thyroid hormone metabolism. In order to investigate any regulation circuits of nis, Cytoscape and the plugin BiNoM [3, 4] were used to perform path analysis of the network to investigate if a path exists from the node iodide going to the node representing "nis transcription". Subsequently, sequential network reduction has led to final model that might explain a putative mechanism behind nis regulation and repetitive iodide administration.

In addition, this map reviews the most-update information about iodide and thyroid hormone metabolism. Besides as a source of information, it can help to elucidate the mode of action of KI on gene transcription after repetitive KI administration.

\section{References}

1. D. Lebsir, L. Manens, S. Grison, P. Lestaevel, T. Ebrahimian, D. Suhard, G. Phan, I. Dublineau, K. Tack, M. Benderitter, A. Pech, J.-R. Jourdain, M. Souidi. Mol. Cell. Endocrinol. (2018), doi: 10.1016/j.mce.2018.02.017 
2. D. Carvalho, C. Dupuy. Mol. Cell. Endocrinol. 458, 6 (2017)

3. P. Shannon, A. Markiel, O. Ozier, N.S. Baliga, J.T. Wang, D. Ramage, N. Amin, B. Schwikowski, T. Ideker. Genome Res. 132498 (2003)

4. E. Bonnet, L. Calzone, D. Rovera, G. Stoll, E. Barillot, A. Zinovyev. BMC Syst Biol. 1 7 (2013) 